\title{
Study on the Evaluation Method of Print Mottle Using Discrete Wavelet Analysis
}

\author{
HUANG Ying \\ State Key Laboratory of Pulp and Paper Engineering \\ South China University of Technology \\ Guangzhou, China \\ e-mail: hy_hubei@163.com
}

\author{
CHEN Guangxue (Corresponding Author) \\ State Key Laboratory of Pulp and Paper Engineering \\ South China University of Technology \\ Guangzhou, China \\ e-mail: chengx@scut.edu.cn
}

\author{
CHEN Qifeng \\ State Key Laboratory of Pulp and Paper Engineering \\ South China University of Technology \\ Guangzhou, China \\ e-mail: qfchen@scut.edu.cn \\ PAN Danhong \\ State Key Laboratory of Pulp and Paper Engineering \\ South China University of Technology \\ Guangzhou, China \\ e-mail: 370250591@qq.com
}

\begin{abstract}
Print mottle is one of the most detrimental factors to general print quality, and to get high quality print, the most important thing is to resolve print mottle problem. The evaluation method for print mottle is proposed by means of discrete wavelet analysis, in which the index of print mottle is built on the base of the coefficient of variance of the wavelet-filtered digital image. Then, in our research, we have compared the three methods: the visual assessment method, the traditional method, and the wavelet-based method. They were applied on offset papers to check their performance. The linear correlation coefficient obtained between the visual ranking of the samples and the results with the traditional method is 0.6148 . While, the correlations using the wavelet-based method with visual evaluation is much better. The print mottle evaluation results with ten wavelet base functions are much better at the third and the fifth decomposition levels. In all, the analytical results compared with visual perception shows that the waveletbased method proposed is effective and practical in measuring printing mottle.
\end{abstract}

Keywords-print mottle; evalution method; discrete wavelet transform; base function; decomposition level

\section{INTRODUCTION}

As we all know, printability of paper and print quality are very important when modern printing applications are considered. Especially in prints containing images, high print quality is a basic requirement. ${ }^{[1]}$ Because of nonideal interactions of paper and ink in high-speed printing processes, there are several un-desired effects in prints. One of these effects is mottling which is related to density and gloss of print. It is the uneven appearance of solid printed areas, and it depends on the printing ink, paper type, and printing process. ${ }^{[2]}$ Mottling can be defined as undesired unevenness in perceived print density. In the ISO/IEC 13660 standard, a more technical definition is given ${ }^{[3]}$ : "aperiodic fluctuations of density at a spatial frequency less than 0.4 cycles per millimeter in all directions". There exists three types of mottling: back-trap mottle (uneven ink absorption in the paper), waterinterface mottle (insufficient and uneven water absorption of the paper causing uneven ink absorption), and ink-trap mottle (wet or dry; in-correct trapping of the ink because of tack). ${ }^{[4]}$

Currently, the print mottle as an indicator to evaluate the paper performance after printing is relatively small. It is basically subjective judgment. Hence the subjective effects are relatively large. In this paper, we provided an evaluation method of print mottle based on the images and the subjective evaluation. In addition, we introduced an alternative approach for measuring mottle defects based on spatial frequency analysis of wavelet-filtered images. It provided a more accurate method to measure the print mottle of papers, and it was useful for printing enterprises to improve print quality.

\section{METHODS}

\section{A. Traditional method}

The mathematical model of the traditional method to detect print mottle is based on the definition of print mottle. As for a digital image $f(x, y)$ containing print mottle, the $\mathrm{CoV}$ (gray value coefficient of variation) may reflect the unevenness of print mottle. The greater the variation of coefficient value, the more obvious the unevenness. Specific steps are as follows:

The image containing print mottle was collected in the computer to get a digital image. After sampling, calculate the average, standard deviation and coefficient of variation of the gray values of the image on the basis of knowledge of mathematical statistics. For ease of calculation, an original image $f(x, y)$ is dispersed into a matrix of size $N \times$ $N$, using the equation (1), (2) and (3) to calculate the coefficient of variation of this image. ${ }^{[5]}$

$$
\bar{f}=\frac{1}{N^{2}} \sum_{x=0}^{N-1} \sum_{y=0}^{N-1} f(x, y)
$$




$$
\begin{gathered}
\sigma_{f}=\sqrt{\frac{1}{N^{2}} \sum_{x=0}^{N-1} \sum_{y=0}^{N-1}[f(x, y)-\bar{f}]^{2}} \\
\operatorname{CoV}=\frac{\sigma_{f}}{\bar{f}}
\end{gathered}
$$

Where, $x, y$ are the horizontal and vertical coordinates of the print mottle discrete image matrix, $f(x, y)$ is the image gray value print mottle discrete matrix, $N$ is the size of the discrete matrix, respectively are the mean and standard gray value, $\mathrm{CoV}$ is the print mottle image variation coefficient matrix of discrete gray values.

\section{B. Wavelet-based method}

The subjective test method is time-consuming and cumbersome to implement quite costly and susceptible to the viewer's own background knowledge, mood and fatigue and other factors, so that subjective test is not realistic in many cases. Some of the existing equipment testing methods are accurate, but they use expensive laboratory equipment, high cost, and it is very difficult to spread. A convenient and effective print mottle evaluation method is necessary.

Discrete ${ }^{[6]}$ and continuous wavelet transforms ${ }^{[7]-[10]}$ have already been used to study base stock formation and, more recently, in connection with solid prints mottle. The scale parameter $a$ was discrete in the continuous wavelet transform process to get the binary wavelet transform. Then, the translation factor $b$ was also discrete to get the discrete wavelet transform. As seen in equation (4) and the inverse transformation was shown in equation (5). Different wavelet base functions in wavelet transform have different treatment effects. ${ }^{[11]}$

$$
\begin{gathered}
W_{f}(j ; k, l)=\frac{1}{2^{j}} \sum_{m=0}^{M-1} \sum_{n=0}^{N-1}\left[f(x, y) \psi\left(\frac{x-k 2^{j}}{2^{j}}, \frac{y-l 2^{j}}{2^{j}}\right)\right] \Delta x \Delta y \\
f(x, y)=\sum_{j ; k, l} W_{f}(j ; k, l) \psi(x, y)
\end{gathered}
$$

Where, $\psi(x, y)$ is the wavelet base function (also called a basic wavelet or mother wavelet), $j$ is an exploded level, $k$ and $l$ are the location information $(j, k, l$ is an integer). $M$ and $N$ are the discrete values.

As for a digital image containing print mottle, it is broken down into two parts: the high frequency part and low frequency part when using two-dimensional wavelet transform. The high frequency portion represents the details of print mottle image. In the two-dimensional wavelet transform, we can get three types of detailed information on each decomposition level. These images contain details on the different spatial directions (horizontal, vertical and diagonal). In this case, a mottle index can be defined by summing the energy of each detail component at a particular level,

Where,

$$
E_{J}=E_{h J}+E_{v J}+E_{d J}
$$

$$
E_{h J}=\sum_{i, j}\left(d_{i, j}^{(h)}\right)^{2}
$$

is the sum of the square of the matrix element of the horizontal detail at level $J$, and likewise for the vertical and diagonal details.

\section{EXPERIMENTS}

\section{A. Making samples}

We present the results for the $100 \mathrm{C} 400$ (400\% cyan, the number of printing is four times) samples. The original samples are approximately $5 \mathrm{~cm} \times 5 \mathrm{~cm}$ in size. The papers used for printing are offset papers. The performance of papers is shown in Table I. The samples were printed using IGT printability tester, where printing pressure is $500 \mathrm{~N}$ (default), the printing speed of $0.2 \mathrm{~m} / \mathrm{s}$ (default), time between printing and set off's of $10 \mathrm{~s}$, inking time of $5 \mathrm{~s}$, the ink film thickness of $8 \mu \mathrm{m}\left(0.35 \mathrm{~cm}^{3}\right)$. The samples were originally scanned with 150 dpi and 16 gray image type using flatbed scanner. Then we got the digital images.

TABLE I. THE CHARACTERIZATIONS OF OFFSET PAPERS

\begin{tabular}{ccccccc}
\hline Papers & $\begin{array}{c}\text { Basis } \\
\text { weight } \\
\left(\mathbf{g} / \mathbf{m}^{\mathbf{2}}\right)\end{array}$ & $\begin{array}{c}\text { Roug } \\
\text { hness } \\
(\boldsymbol{\mu m})\end{array}$ & $\begin{array}{c}\text { Opaci } \\
\text { ty } \\
(\mathbf{\%})\end{array}$ & $\begin{array}{c}\text { Gloss } \\
\left.\mathbf{( 6 0}^{\circ}\right)\end{array}$ & $\begin{array}{c}\text { Whiten } \\
\mathbf{e s s} \\
(\mathbf{\%} \text { ISO) }\end{array}$ & $\begin{array}{c}\text { Unifo } \\
\text { rmity }\end{array}$ \\
\hline $1^{\#}$ & 68 & 4.34 & 92.54 & 3.85 & 99.79 & 72.15 \\
$2^{\#}$ & 98 & 4.79 & 98.56 & 3.83 & 97.95 & 85.68 \\
\hline
\end{tabular}

\section{B. Visual assessment}

The characterization and evaluation of print mottle is a crucial step in the assessment of the printing quality of papers and boards. This assessment is however a subjective phenomenon and is usually evaluated by a set of independent observers. We circulated a set of 100 mottling samples, and asked the human observers to evaluate the perceived mottling. All observers must have normal vision, and they should be trained how to evaluate the print mottle before the evaluation. All the samples were observed under the same conditions. The score was limited to 1 to 3 . The mean values of these subjective assessments were used as initial reference mottling indices against which the results of all the other vision methods were compared. To ensure the reliability of the results, select 30 samples evaluated print mottle was printed from the 100 samples. The visual assessment results obtained are as follows:

$\mathrm{V}=\left[\begin{array}{llllllllllll}2.65 & 1.8 & 1.4 & 0.7 & 0.85 & 1.9 & 1.8 & 0.5 & 2.0 & 0.65 & 2.5 & 3.0\end{array}\right.$

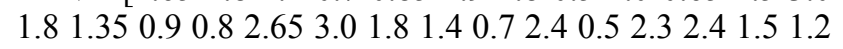
$\begin{array}{llll}0.5 & 0.4 & 2.7]\end{array}$
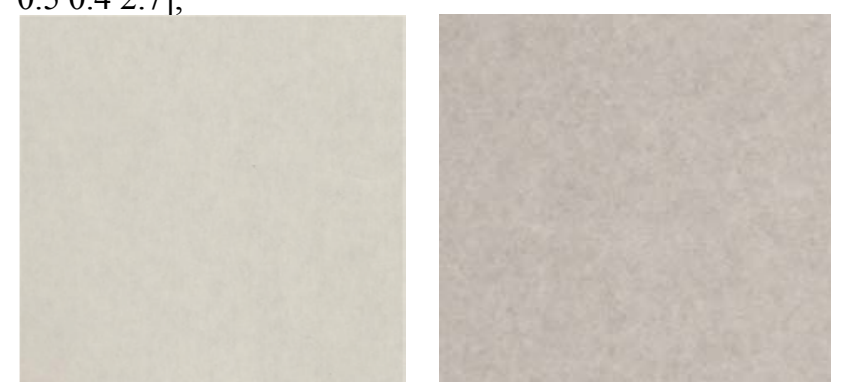

Figure. 1. Mottling assessments: (a) sample 28, one of the better sample, with visual ranking of 0.5 ; (b) sample 1 , in the lowest end of print quality, with visual ranking of 2.65

\section{Traditional method}

Using traditional methods to build a mathematical model of print mottle, the MATLAB software is used for the above process to be realized. The $\mathrm{CoV}$ value is the print mottle image variation coefficient matrix of discrete gray values. The results of print mottle for 30 samples with the traditional method can be seen in Table II. 
TABLE II. THE PRINT MOTTLE OF 30 SAMPLES WITH THE TRADITIONAL METHOD

\begin{tabular}{cccccc}
\hline Samples & $\boldsymbol{C o V}$ & Samples & $\boldsymbol{C o V}$ & Samples & $\boldsymbol{C o V}$ \\
\hline 1 & 0.2382 & 11 & 0.0987 & 21 & 0.1125 \\
2 & 0.1761 & 12 & 0.2467 & 22 & 0.0729 \\
3 & 0.1234 & 13 & 0.2395 & 23 & 0.1201 \\
4 & 0.0756 & 14 & 0.1660 & 24 & 0.2315 \\
5 & 0.1010 & 15 & 0.1108 & 25 & 0.2493 \\
6 & 0.2492 & 16 & 0.0732 & 26 & 0.1784 \\
7 & 0.2370 & 17 & 0.1169 & 27 & 0.1212 \\
8 & 0.1735 & 18 & 0.2323 & 28 & 0.0696 \\
9 & 0.1197 & 19 & 0.2372 & 29 & 0.0897 \\
10 & 0.0785 & 20 & 0.1634 & 30 & 0.2469 \\
\hline
\end{tabular}

We analyzed the correlation between the results obtained by the traditional method with the visual assessment, the analysis results were shown in Fig. 2.

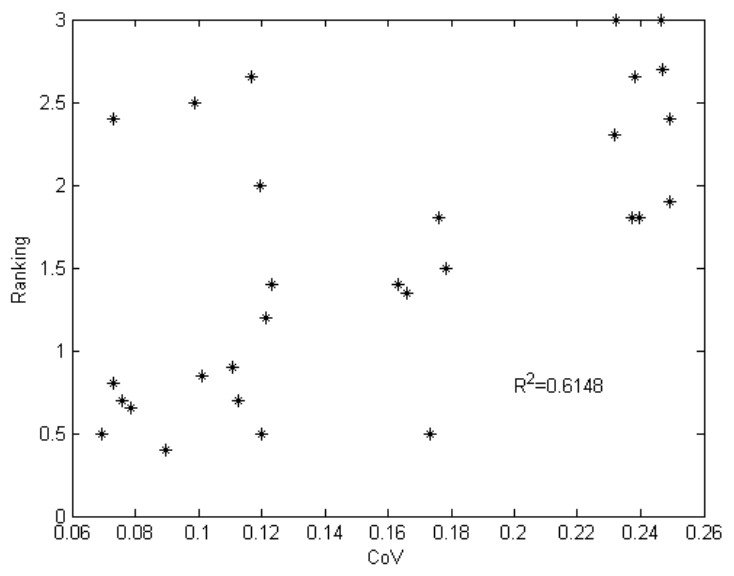

Figure. 2. Linear correlation coefficients obtained between the visual ranking of the samples and the results with the traditional method

As we can see from Fig.2, it is not very good when using traditional method to establish print mottle evaluation model for offset papers, the correlation coefficient with visual assessment is just 0.6148 .

\section{Wavelet-based method}

A wavelet analysis of the digitized images already gives a lot of information on its structure. The wavelet base functions are spatially localized and as such give information on both the scale and frequency of the variations. It is this versatility that has made the technique an important tool in image analysis and related fields. The advantages of discrete wavelet transforms is that there exist fast pyramidal algorithms to decompose the image into details and approximation. For example, the haar wavelet at the fifth decomposition level, the results shown in Table III. We used standard discrete wavelet basis: the haar wavelet, sym3, sym4, sym5, the Daubechies with 1, 2, 4,5 and 6 coefficients and bior3.7 wavelet, in addition, the decomposition level is $1 \sim 5$. Under the same conditions, the wavelet was used to analyze the print mottle of offset papers, and analyze the correlation between the method and a human visual evaluation system (HVS). Then the results were shown in Table IV.

TABLE III. THE PRINT MOTTLE OF 30 SAMPLES WITH THE HAAR BASE FUNCTION WAVELET METHOD AT THE FIFTH DECOMPOSITION LEVEL

\begin{tabular}{cccccc}
\hline Samples & $\boldsymbol{E}_{\boldsymbol{J}}$ & Samples & $\boldsymbol{E}_{\boldsymbol{J}}$ & Samples & $\boldsymbol{E}_{\boldsymbol{J}}$ \\
\hline 1 & 6.0444 & 11 & 0.3697 & 21 & 1.3363 \\
2 & 3.3000 & 12 & 6.4221 & 22 & 0.5447 \\
3 & 1.6142 & 13 & 6.1090 & 23 & 0.4250 \\
4 & 0.5973 & 14 & 2.9325 & 24 & 5.6437 \\
5 & 0.4050 & 15 & 1.2981 & 25 & 6.6182 \\
6 & 6.5810 & 16 & 0.5477 & 26 & 3.3888 \\
7 & 5.9835 & 17 & 0.3992 & 27 & 1.5477 \\
8 & 3.2029 & 18 & 5.6885 & 28 & 0.5059 \\
9 & 1.5155 & 19 & 5.9946 & 29 & 0.3424 \\
10 & 0.6362 & 20 & 2.8399 & 30 & 6.4547 \\
\hline
\end{tabular}

TABLE IV. LINEAR CORRELATION COEFFICIENTS OBTAINED BETWEEN THE VISUAL RANKING OF THE SAMPLES AND THE RESULTS WITH TRADITIONAL METHOD

\begin{tabular}{cccccc}
\hline $\begin{array}{c}\text { Wavelet } \\
\text { base } \\
\text { functions }\end{array}$ & $\begin{array}{c}\text { One } \\
\text { level }\end{array}$ & $\begin{array}{c}\text { Two } \\
\text { level }\end{array}$ & $\begin{array}{c}\text { Three } \\
\text { level }\end{array}$ & $\begin{array}{c}\text { Four } \\
\text { level }\end{array}$ & $\begin{array}{c}\text { Five } \\
\text { level }\end{array}$ \\
\hline haar & 0.7742 & 0.8732 & 0.9613 & 0.7742 & $\mathbf{0 . 9 6 9}$ \\
sym3 & 0.6616 & 0.7936 & $\mathbf{0 . 9 5 4 1}$ & 0.6616 & 0.9375 \\
sym4 & 0.6518 & 0.787 & $\mathbf{0 . 9 5 4}$ & 0.6518 & 0.9322 \\
sym5 & 0.6476 & 0.7892 & $\mathbf{0 . 9 5 6 3}$ & 0.6476 & 0.9171 \\
$\mathrm{db} 1$ & 0.7742 & 0.8732 & 0.9613 & 0.7742 & $\mathbf{0 . 9 6 9}$ \\
$\mathrm{db} 2$ & 0.6907 & 0.815 & 0.9561 & 0.6907 & $\mathbf{0 . 9 6 4 1}$ \\
$\mathrm{db} 4$ & 0.649 & 0.7889 & $\mathbf{0 . 9 5 5 9}$ & 0.649 & 0.9151 \\
$\mathrm{db} 5$ & 0.644 & 0.7753 & $\mathbf{0 . 9 5 3 5}$ & 0.644 & 0.8969 \\
$\mathrm{db} 6$ & 0.6428 & 0.7728 & $\mathbf{0 . 9 5 5 1}$ & 0.6428 & 0.8641 \\
\hline $\mathrm{bior} 3.7$ & 0.645 & 0.6775 & $\mathbf{0 . 9 1 4 8}$ & 0.645 & 0.8246 \\
\hline
\end{tabular}

In Table IV, the results of using wavelets to evaluate the print mottle of offset papers at one to five decomposition level was higher than that of the traditional method whose result is 0.6148 . Particularly, the results at the third and fifth decomposition level evaluated have a very good correlation with the human visual system. Thus the optimal parameters should select in the third and the fifth decomposition levels for offset papers using different wavelet base functions. Also it can be seen, although the result of the process using different wavelet base functions has some small differences, within the optimal parameters, the lowest correlation coefficients is over 0.6148 , therefore, this method is an effective evaluation of print mottle approach. 


\section{CONCLUSIONS}

Three different ways (the visual assessment, the traditional method, and the wavelet-based method) to compute a mottle index are introduced. The linear correlation coefficient obtained between the visual ranking of the samples and the results with the traditional method is 0.6148 . While, the correlations using the wavelet-based method with visual evaluation is better. The print mottle evaluation results with ten wavelet base functions are much better at the third and the fifth decomposition levels. In all, the analytical results compared with visual perception shows that the new method using discrete wavelet analysis to evaluate paper print mottle is simpler and more objective. It's more convenient to solve some problems caused by print mottle, and then improve the printing quality. It has some practical value for analyzing and solving various paper print mottle problem.

\section{REFERENCES}

[1] Smith, David. "Update \& overview on mottle in offset printing," Paper Conference and Trade Show 2010, PaperCon 2010, pp.168212.

[2] A. Sadovnikov, P. Salmela, L. Lensu. "Mottling assessment of solid printed areas and its correlation to perceived uniformity," Lec-ture Notes in Computer Science, 2005(3540): pp. 409-418.

[3] ISO: ISO/IEC 13660: 2001(e) standard. Information technology office equipment measurement of image quality attributes for hardcopy output binary monochrome text and graphic images. ISO/IEC (2001).
[4] Sandreuter, P. Nancy. "Predicting print mottle a method of differentiating between three types of mottle," Tappi Journal, 1994, vol. 77(7), pp. 173-187.

[5] XU Lu-ping. Digital image processing and study guide. Beijing: Science Press, 2009.

[6] LIU Guodong, Z. Meiyun, L. Qiaoping. "Study on the assessment method of print mottle using discrete wavelet analysis," 2012 second China Academic Conference on Printing and Pack-aging. 2012.

[7] J-P. Bernie, H. Pande, and R. Gratton. "A new wavelet-based instrumental method for measuring print mottle," Pulp. Pap. Can. vol. 105 (9), pp. 24-26 (September 2004).

[8] M. Kellomaki, J.J. Pawlak, Y-J. Sung, and D. S. Keller, "Characterization of the spatial variability of paper formation using a continuous wavelet trans-form", The Science of Papermaking, 12th Funda-mental Research Symposium, Oxford UK, vol.2, pp 1313-1342 (2001).

[9] E. Lieng, "Wavelet analysis in paper formation determination," Proceedings of the 2004 Progress in Paper Physics Seminar, O. W. Gregersen, Trondheim (2004).

[10] LIU Guodong; ZHANG. Meiyun; WANG. Qian. "An evaluation method for print mottle using wavelet denoising and image grey level intensity gradient," Nordic Pulp and Paper Research Journal, 2014, vol. 29(2), pp. 280-285.

[11] WANG Qian, XU Yongjian. Research on Detecting Method for Print Mottle and Paper Formation using Digital Image Analysis Technology. XI'AN: Shanxi University of Science and Technology. 2014 